\title{
Homelessness and the length of stay in psychiatric wards
}

\begin{abstract}
Aims \& methods: To study the effects of homelessness on length of stay in psychiatric wards. All 37 admissions of homeless people to an acute psychiatric service during the year 2005 were identified using the Carebase system. Admissions of homeless people were then compared to a random sample (of 62 admissions) from the total number of admission during 2005 (397 admissions)
\end{abstract}

Results: Homeless patients were more likely to be younger, male and single compared to the random sample. A significantly higher proportion of the homeless patients had the diagnosis of schizophrenia. The mean length of stay of the homeless patients was significantly higher; 112 days compared to 33 days for the random sample (almost 4 times).

Clinical implication: Homeless patients have significantly longer admissions than patients in general. This has implications in terms of costs, increased service use and greater risk of institutionalisation. This needs to be considered in planning residential and other community services for homeless psychiatric patients.

Keywords: homeless patients, psychiatric disorders, substance abuse, risk factors, no fixed abode
Volume 3 Issue 6 - 2017

\author{
Walid Khalid Abdul-Hamid,' Shefalica Bhan- \\ Kotwal, ${ }^{2}$ Pratap Kovvuri, ${ }^{3}$ Stephen Stansfeld' \\ 'Barts and The London Queen Mary's School of Medicine and \\ Dentistry, UK \\ ${ }^{2}$ Clacton and district general hospital, UK \\ 3Middlemore Hospital, New Zealand
}

\begin{abstract}
Correspondence: Walid Khalid Abdul-Hamid, Honorary Senior Lecturer, Centre for Psychiatry, Barts and The London Queen Mary's School of Medicine and Dentistry, Consultant Psychiatrist, The Linden Centre, Chelmsford, Essex, UK, Email walid.abdul-hamid@nhs.net
\end{abstract}

Received: August 05, 2017 | Published: August 21, 2017

\section{Introduction}

With the deepening economic crisis and the current housing benefit curbs there are concerns that the homelessness of the mentally ill will continue to be a significant issue for psychiatric services. ${ }^{1}$ Much research supports the view that homelessness is associated with psychiatric disorders and closure of psychiatric hospitals ${ }^{2-4}$ and few studies oppose it. ${ }^{5,6}$ Many worried that the closure of mental institutions would lead homeless psychiatric patients to become 'revolving door' admissions. ${ }^{2,5}$ Studies on the admission of homeless patients to psychiatric ward continue to show that the problem of the homeless mentally ill is far from over. Appleby \& Desai ${ }^{7}$ in an analysis of admission to psychiatric wards in Chicago found that the rate of homelessness among psychiatric admissions had increased substantially over the 1980's and was even higher among applicants for hospitalization.

The long admissions of the homeless mentally ill continue to be a burden on psychiatric services. Sharon et al. ${ }^{8}$ looked at hospitaldischarge data on 18,864 admissions of homeless adults to New York City's public general hospitals and compared it to other low-income adults to all general hospitals in New York City during 1992 and 1993. Of the admissions of homeless people, 51.5 percent were for treatment of substance abuse or mental illness, as compared with 22.8 percent for the other low-income patients. The homeless patients stayed 4.1 days, or 36 percent longer per admission on average than the other patients, even after adjustments were made for differences in the rates of substance abuse and mental illness. The costs of the additional days per discharge averaged $\$ 4,094$ for psychiatric patients. The authors concluded that homelessness is associated with substantial excess costs per hospital stay in New York City. Planning community services for the homeless should take in consideration the high costs of hospitalization in this population without such services. Adams et al. ${ }^{9}$ found that homeless veterans were more likely to be admitted to hospital when they presented with psychiatric and substance abuse diagnoses (79.9\%), compared with housed veterans (29.1\%).
However, not all studies found that homeless patients have longer hospital admissions. Lowens et al. ${ }^{10}$ compared 50 homeless men with a control group of non-homeless patients (matched by diagnosis). The median length of hospitalisation was 26 days with no significant differences between the two groups. Outpatient treatment was planned for only $16 \%$ of the homeless patients compared with $40 \%$ of the controls. Lauber et al. ${ }^{11}$ looked into admission to psychiatric hospitals between in 1996-2001 from a defined area in Switzerland. They compared those who were homeless at discharge with other psychiatric inpatients. In contrast, to previous studies the authors found that homeless patients at discharge had a shorter length of inpatient stay. The shortened length of admission might have happened as a result of the discharge of some patients (no numbers were given) without housing provision. The authors suggested that risk factors for being homeless at discharge were: homelessness prior to admission, not having a relationship, the presence of multiple substance abusers or a dual diagnosis, lack of significant clinical improvement during inpatient treatment and being discharged against medical advice. The current study aimed to describe the outcome (in terms of length of stay and discharge address) of the psychiatric admissions of patients with no fixed abode (NFA) status compared with home-based patients who were admitted to the Linden Centre at Chelmsford Essex during a period of one year.

\section{Method}

All admissions to psychiatric wards at the North Essex Mental Health Partnership NHS Trust are entered into a computerized recording system 'Carebase'. All the admissions to the Linden Centre (which is the admission facility for the Central sector of the trust during the year (2005) were identified using the Carebase system. This study was undertaken on all the NFA (no fixed abode) admissions to the Linden Centre over the year 2005 (January to December). The authors labeled patients as homeless based on them having NFA status on admission. All the 37 NFA admissions were included in this study and they were then compared to a random sample (of 62 admissions) 
- using random numbers tables - from the total number of 397 admissions during 2005. A pre-designed questionnaire was used then to collect data from the case-notes of both the NFA sample and the random control sample. Data were entered on the Statistical Package for Social Sciences (SPSS). The same package was used to analyse the data using Chi-square statistical test to compare the variables and outcomes of the two groups.

\section{Results}

\section{Demographic features}

There were many differences in the demographic features between the homeless patients and those patients from the random sample (Table 1). The homeless patients were younger, their mean age was 36 years $(\mathrm{SD}=11.5)$ compared to 42 years $(\mathrm{SD}=13)(\mathrm{t}$ test $=-2.2, \mathrm{P}=0.03)$. In the random sample, $64 \%$ of the NFA patients were 35 years (this age was chosen based on mean age to create comparable groups) or under compared to only $30 \%$ of the random sample patients in this age group (Chi-square $=10, \mathrm{P}=0.001)$. A higher proportion of the homeless patients were male ( $68 \%$ compared to $50 \%$ of the random sample). The marital status of the homeless patients was more likely to be single ( $73 \%$ compared to $40 \%$ of the random sample patients) while the random sample were more likely to be married (26\% compared to $11 \%$ of the homeless patients) or divorced ( $22 \%$ compared to $5 \%$ of the homeless patients).

Table I Demographic features

\begin{tabular}{llll}
\hline $\begin{array}{l}\text { Demographic } \\
\text { details }\end{array}$ & Homeless & Not homeless & $\begin{array}{l}\text { Odds ratio } \\
(95 \% \text { C.I.) }\end{array}$ \\
\hline Age & & & \\
\hline I7-35Yrs* & $63.90 \%$ & $30.00 \%$ & $4.0(1.8-10)$ \\
$36-45$ Yrs & $25.00 \%$ & $26.70 \%$ & $0.9(0.3-2.6)$ \\
$46-55$ Yrs & $8.30 \%$ & $21.70 \%$ & $0.3(0.1-1.4)$ \\
$>56$ Yrs & $2.80 \%$ & $21.70 \%$ & $0.1(0.01-0.8)$ \\
\hline Sex & & & $3.0(0.9-5)$ \\
\hline Male & $67.60 \%$ & $50.00 \%$ & \\
Female & $32.40 \%$ & $50.00 \%$ & $0.3(0.08-1.2)$ \\
\hline Marital Status & & & $4.0(1.4-11.2)$ \\
\hline Married & $10.80 \%$ & $25.90 \%$ & $0.2(0.03-1)$ \\
Single* & $73.00 \%$ & $39.70 \%$ & - \\
Divorced & $5.40 \%$ & $22.40 \%$ & $1.3(0.3-6.1)$ \\
Widowl & $0.00 \%$ & $3.40 \%$ & \\
Widower & $10.80 \%$ & $8.60 \%$ & \\
Separated & & & \\
\hline
\end{tabular}

*Statistically significant at $5 \%$ level

\section{Clinical presentation and history}

There were significant differences in the clinical presentation of the two groups (Table 2). A significantly higher proportion of the homeless patients had a primary diagnosis of schizophrenia (37\% compared to $12 \%$ of the random sample patients, statistically significant as Chi-square-8.6, $\mathrm{P}=0.003, \mathrm{OR}=4.5$ ). Substance abuse problems were the primary diagnosis for $29 \%$ of the homeless patients compared to $15 \%$ of the random sample patients. Primary diagnoses of neurotic and personality disorders (29\% compared to $9 \%$ of the homeless patients) and affective disorders (33\% compared with 17\% in the homeless patients) were more frequent in the random sample patients. Further questions on the presence or absence of substance misuse showed that $76 \%$ of homeless patients presented with alcohol problem compared to $58 \%$ of the random sample patients. Illicit drugs misuse was found in $60 \%$ of the homeless patients compared with $30 \%$ of the random sample patients. The most worrying finding was that $27 \%$ of the homeless patients misused prescribed drugs compared to $5 \%$ of the random sample patients.

Table 2 Clinical features and history

\begin{tabular}{|c|c|c|c|}
\hline Diagnosis & Homeless & $\begin{array}{l}\text { Random } \\
\text { sample }\end{array}$ & $\begin{array}{l}\text { Odds ratio } \\
\text { (95\% C.I.) }\end{array}$ \\
\hline Schizophrenia* & (I3) $37 \%$ & (7) $12 \%$ & $4.5(1.6-13)$ \\
\hline Substance Abuse & (13) $37 \%$ & (II) $18 \%$ & $3(0.9-8)$ \\
\hline Affective Disorders & (6) $17 \%$ & (I8) $33 \%$ & $0.5(0.1-1.5)$ \\
\hline $\begin{array}{l}\text { Neurosis/ Personality } \\
\text { Disorder }\end{array}$ & (3) $9 \%$ & (I7) $29 \%$ & $0.8(0.001-3.5)$ \\
\hline Others & 0 & (7) $12 \%$ & - \\
\hline
\end{tabular}

\section{*Statistically significant at $5 \%$ level}

The psychiatric history showed that the proportion of those who had no previous admissions was similar in the 2 groups $(16 \%$ in the homeless patients compared to $18 \%$ in the random sample patients). However, $70.3 \%$ of the homeless patients had more than one admission compared to $52.4 \%$ of the random sample patients. The mean length of stay of the homeless patients was significantly higher than that of the random sample. Homeless patients mean length of stay during the study year was 112 days $(\mathrm{SD}=136.8)$ compared to 33 days $(\mathrm{SD}=44.4)$ for the random sample patients (statistically significant as $\mathrm{T}=4.1, \mathrm{P}=0.001, \mathrm{CI}=41.6-116.8$ ).

\section{Accommodation at admission and on discharge (Table 3)}

On admission, all the homeless patients had no fixed abode status compared to only $5.2 \%$ of the random sample patients. Prior to admission the random sample patients were housed in privately rented accommodation $38 \%$, other rented accommodation in $16 \%$, council accommodation in $24 \%$, bed and breakfast accommodation in $7 \%$ and supported accommodation in $10 \%$. On discharge, $27 \%$ of the homeless patients were discharged to no fixed abode status, $32 \%$ had moved to supported accommodation, $27 \%$ to council accommodation and $5.4 \%$ moved to private accommodation.

Table 3 Accommodation on Admission and on discharge

\begin{tabular}{llll}
\hline Accommodation & Homeless & $\begin{array}{l}\text { Random } \\
\text { sample }\end{array}$ & $\begin{array}{l}\text { Odds ratio } \\
\text { (C.I.) }\end{array}$ \\
\hline On admission & $37(100 \%)$ & $3(5.2 \%)$ \\
\hline $\begin{array}{l}\text { No Fixed Abode } \\
\text { Private Accomodation }\end{array}$ & $22(37.9 \%)$ \\
Rented Accomodation & $9(15.5 \%)$ \\
Council Accomodation & & $14(24.1 \%)$ \\
Bed and Breakfast & & $4(6.9 \%)$ \\
Supported accomodation & & $6(10.3 \%)$ \\
\hline On discharge & & $2(3.4 \%)$ \\
\hline No Fixed Abode & $10(27.0 \%)$ & $23(39.0 \%)$ \\
Private Accomodation & $2(5.4 \%)$ & $9(15.3 \%)$ \\
Rented Accomodation & $1(2.7 \%)$ & $18(30.5 \%)$ \\
Council Accomodation & $10(27.0 \%)$ & 0 \\
Bed and Breakfast & $1(2.7 \%)$ & $7(11.9 \%)$ \\
Supported & $12(32.4 \%)$ & \\
accomodation & &
\end{tabular}




\section{Discussion}

Homeless patients admitted to the Linden centre in the year 2005 were compared in this study to a random sample of admissions of that same year. The homeless patients were younger, mostly male and single compared to the random sample. It was worrying to discover that a significantly higher proportion of the homeless patients had a diagnosis of schizophrenia. Homeless patients also have twice the rate of diagnosis of alcohol related problems. Contrary to common belief the homeless sample had a significantly lower prevalence of the diagnosis of personality disorder. This diagnostic picture might be coloured by the social class of the patients so that homeless patients are more likely to have the diagnosis of schizophrenia as used to happen in US in the 1950s. ${ }^{12}$ This could more likely be explained by social drift of patients with schizophrenia and impaired functioning into poverty and homelessness. ${ }^{13}$ Personality Disorder diagnosis has been associated with complex trauma and recent work by Nick Maguire indicated the presence of high prevalence of complex trauma in this population. ${ }^{14}$

A significantly higher proportion of the homeless patients had more than one admission. The length of admission was strikingly high in the homeless group (almost 4 times that of random sample). This may be the result of difficulties in finding suitable accommodation after discharge and the complexities of dealing with dual diagnosesthese two factors may also interact. This clearly has significant cost implications if homeless patients have more frequent and longer admissions. With the current financial crisis, this fact needs to be considered in planning residential and other community services for the homeless psychiatric patients as this will result in saving of the high costs involved in homeless people prolonged hospital admission.

The accommodation to which patients were discharged showed that almost a third of the homeless were discharged to homelessness. On further analysis, we found that $30 \%$ of those discharged to homelessness had the diagnosis of schizophrenia. Discharge to stressful environmental conditions is likely to lead to further relapse and to further hospital admissions. This human cost should also be considered making sure that adequate accommodation with flexible levels of support should be available in the community to ensure the adequate and effective treatment of homeless psychiatric patients both in hospital and in the community. The Department of Health recommends the integration of therapeutic interventions with housing solutions and suggesting that mental health services should be provided in collaboration with housing provision. ${ }^{15}$

\section{The recommendations of this study could be summarised by the following}

a. The appointment of a discharge coordinator at the North Essex Partnership NHS Trust to liaise with housing agencies to ensure housing provision for patients discharged from inpatients wards.

b. To repeat this investigation after the appointment of the discharge coordinator to evaluate the effectiveness of such appointment. c. Bigger and better funded national study to evaluate the problem of homeless people admitted to psychiatric wards.

\section{Acknowledgements}

None.

\section{Conflict of interest}

The author declares no conflict of interest.

\section{References}

1. Wintour P. Welfare minister seeks a new definition of homelessness. Guardian. Co. UK; 2010.

2. Weller BGA, Weller MPI, Coker E, et al. Crisis at Christmas 1986. The Lancet. 1987;1(8532):553-554.

3. Desai MM, Rosenheck RA. Unmet need for medical care among homeless adults with serious mental illness. Gen Hosp Psychiatry. 2005;27(6):418-425.

4. Henderson C, Bainbridge J, Keaton K, et al. The use of data to assist in the design of a new service system for homeless veterans in New York City. Psychiatr Q. 2008;79(1):3-17.

5. Timms PW, Fry AH. Homelessness and mental illness. Health Trends. 1989;21(3):70-71.

6. Marshall M. Collected and neglected: Are Oxford hostels for the homeless filling up with disabled psychiatric patients? British Medical Journal. 1989;299:706-709.

7. Appleby L, Desai PN. Documenting the relationship between homelessness and psychiatric hospitalization. Hosp Community Psychiatry. 1985;36(7):732-737.

8. Salit SA, Kuhn EM, Hartz AJ, et al. Hospitalization costs associated with homelessness in New York City. N Engl J Med. 1998;338(24):1734 1740 .

9. Adams J, Rosenheck R, Gee L, et al. Hospitalized younger: a comparison of a national sample of homeless and housed inpatient veterans. $J$ Health Care Poor Underserved. 2007;18(1):173-184.

10. Lowens S, Kellinghaus C, Eikelmann B, et al. Homeless men in inpatient psychiatric treatment-a controlled study. Effects of treatment. Psychiatr Prax. 2000;27(1):24-27.

11. Lauber C, Lay B, Rössler W. Homeless people at disadvantage in mental health services. Eur Arch Psychiatry Clin Neurosci. 2006;256(3):138145 .

12. Hollingshead AB, Redlich FC. Social class and mental illness: a community study 1958. Am J Public Health. 2007;97(10):1756-1757.

13. Goldberg EM, Morrison SL. Schizophrenia and social class. British Journal of Psychiatry. 1963;109(463):785-802.

14. Maguire N, Johnson R, Vostanis P, et al. Homelessness and complex trauma a review of the literature. Southampton, UK; 2009.

15. Healthcare for Single Homeless People. Department of Health, London, UK; 2010. p. 1-44. 